\title{
Incremental Cost of Prematurity by Week of Gestational Age
}

\author{
Eileen M. Walsh, RN, MPH ${ }^{1}$ Sherian X. Li, MS ${ }^{1}$ Libby K. Black, Pharm.D., 2** \\ Michael Kuzniewicz, MD, MPH ${ }^{1,2, *}$ \\ ${ }^{1}$ Division of Research, Kaiser Permanente, Oakland, California \\ ${ }^{2}$ Global Health Outcomes, Recro Pharma, Malvern, Pennsylvania \\ ${ }^{3}$ Division of Neonatology, Kaiser Permanente Northern California, \\ Oakland, California \\ Address for correspondence Eileen M. Walsh, RN, MPH, Division of \\ Research, Kaiser Permanente, 2000 Broadway, Oakland, CA 94612 \\ (e-mail: eileen.m.walsh@kp.org).
}

Am J Perinatol Rep 2019;9:e76-e83.

\begin{abstract}
Keywords

- preterm birth

- health care costs

- utilization

- neonatal intensive care

Objective This study was aimed to compare health care costs and utilization at birth through 1 year, between preterm and term infants, by week of gestation.

Methods A cross-sectional study of infants born at $\geq 23$ weeks of gestational age (GA) at Kaiser Permanente Northern California facilities between 2000 and 2011, using outcomes data from an internal neonatal registry and cost estimates from an internal cost management database. Adjusted models yielded estimates for cost differences for each GA group. Results Infants born at 25 to 37 weeks incur significantly higher birth hospitalization costs and experience significantly more health care utilization during the initial year of life, increasing progressively for each decreasing week of gestation, when compared with term infants. Among all very preterm infants ( $\leq 32$ weeks), each 1-week decrease in GA is associated with incrementally higher rates of mortality and major morbidities. Conclusion We provide estimates of potential cost savings that could be attributable to interventions that delay or prevent preterm delivery. Cost differences were most extreme at the lower range of gestation ( $\leq 30$ weeks); however, infants born moderately preterm (31-36 weeks) also contribute substantially to the burden, as they represent a higher proportion of total births.
\end{abstract}

Despite many advances in neonatology and resultant improvement in neonatal mortality, we have yet to solve the underlying problem of preterm labor (PTL), as we do not fully comprehend its multifactorial etiology. Current obstetrical practices, such as cerclage and tocolytics, have been ineffective in improving neonatal outcomes. ${ }^{1,2}$ Randomized control trials have shown that progesterone treatment reduces the risk of preterm delivery before 37 weeks in mothers with an increased risk of preterm delivery; however, those mothers need to be identified early and weekly treatment started between 16 and 24 weeks. ${ }^{3}$ Numerous studies and large databases show the incremental decrease in neo-

\footnotetext{
Study contributions while at Glaxo Smith Kline, Value Evidence \& Outcomes, NC, USA.
}

received

October 23, 2018 accepted after revision December 30, 2018
DOI https://doi.org/

10.1055/s-0039-1683934. ISSN 2157-6998. natal morbidities with each subsequent gain in week of gestational age (GA). ${ }^{4-9}$ Delaying delivery, even 1 to 2 weeks, has a tremendous impact on these morbidities as well as costs. Previous studies ${ }^{10-27}$ have examined the potential cost savings associated with increased GA, but these have primarily relied on administrative data, with hospital costs based on cost-charge ratios, or were single-center studies, or simply were performed over a decade or two ago. The aim of this study is to compare costs of infants born preterm to the costs of infants born at term, including the costs of neonatal care for the initial hospitalization and of care (both inpatient and outpatient) required in the 1 st year of life, by week of gestation. This is intended to inform potential cost savings that may arise because of interventions that delay preterm delivery. To do this, we employed a modern

Copyright @ 2019 by Thieme Medical Publishers, Inc., 333 Seventh Avenue, New York, NY 10001, USA. Tel: +1(212) 584-4662.
License terms

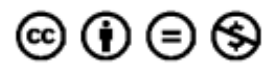


dataset, using a quasi-population based sample, and cost data from an integrated medical system.

\section{Methods}

\section{Study Design and Population}

This is a cross-sectional study of infants born at $\geq 23$ weeks of GA at a Kaiser Permanente, Northern California (KPNC) facility between January 2000 and December 2011, in any of 14 KPNC facilities. KPNC is an integrated health care delivery system that currently provides coverage to $>30 \%$ of the insured population in Northern California, with approximately 4 million members. In KPNC, all inpatient and outpatient care is tracked through a common medical record number. Our objective was to compare routine costs of care among infants of different GAs through 1 year of life. From the base population of infants born in any KPNC facility within the study time frame $(360,665)$, we excluded infants who were born at or transferred during the birth hospitalization to any non-KPNC facilities which do not use KPNC clinical data systems (12,141), did not have records in the cost database (98), or had negative values in the cost database (276).

The resulting study cohort used for comparisons of cost and rates of morbidities during the birth hospitalization includes 348,150 infants of whom $303,233(87.1 \%)$ were born at term $(\geq$ 38 weeks). Of the 12,515 excluded infants, 10,673 (85.3\%) were born at term. Infants who died during the birth hospitalization were retained in the analytic cohort for comparisons of birth hospitalization costs and outcomes. For analyses of costs and utilization during the initial year of life, we excluded infants with incomplete membership for the year 1 follow-up period, defined as no record of health plan enrollment after age 6 months $(83,298)$ or no cost data for the year 1 follow-up period (103), resulting in a cohort of 264,749 for the comparisons of costs and utilization in the initial year of life. - Fig. 1 shows the cohort compilation process for the birth hospitalization and 1 st year follow-up cohorts.

\section{Infant Characteristics}

GA was determined from the maternal record and defined according to the obstetrically assigned estimated date of delivery (EDD). For women with regular menstrual cycles, EDD is based on last menstrual period if in 7-day agreement with a first trimester ultrasound. For women with irregular menstrual cycles, EDD is determined from first trimester ultrasound results. Small for GA (SGA) and large for GA (LGA) statuses were determined by plotting the infant's weight and GA on the Fenton's curves, ${ }^{28}$ using $<5$ th percentile as the cut-off for SGA, and $>$ 95th percentile for LGA.

\section{Neonatal Morbidities}

For infants admitted to a level III neonatal intensive care unit (NICU), we obtained detailed information on complications and interventions occurring during the NICU admission from the KPNC neonatal minimum data set (NMDS). ${ }^{29}$ Data in the NMDS are captured through automated extraction from the electronic medical record, augmented by verification of extracted data and manual abstraction of complex variables by trained medical record abstractors. The following diagnoses and procedures were included for this analysis: necrotizing enterocolitis (Bell's stage $\geq \mathrm{II})^{30}$ mechanical ventilation for 7 or more days, chronic lung disease defined as need for supplemental oxygen at 36 weeks corrected GA, severe intracranial hemorrhage (grade III or IV), severe retinopathy of prematurity (stage $\geq$ III or requiring intervention), early- or late-onset sepsis, and mortality after discharge. Standardized definitions of the above neonatal diagnoses are adapted from the Vermont Oxford Network data definitions. ${ }^{31}$

\section{Estimates of Costs}

Data on the use and cost of medical care was obtained from linked automated clinical and administrative databases at Kaiser Permanente. The Kaiser Permanente cost management information system (CMIS) provides the costs of hospital services and outpatient clinic services that were

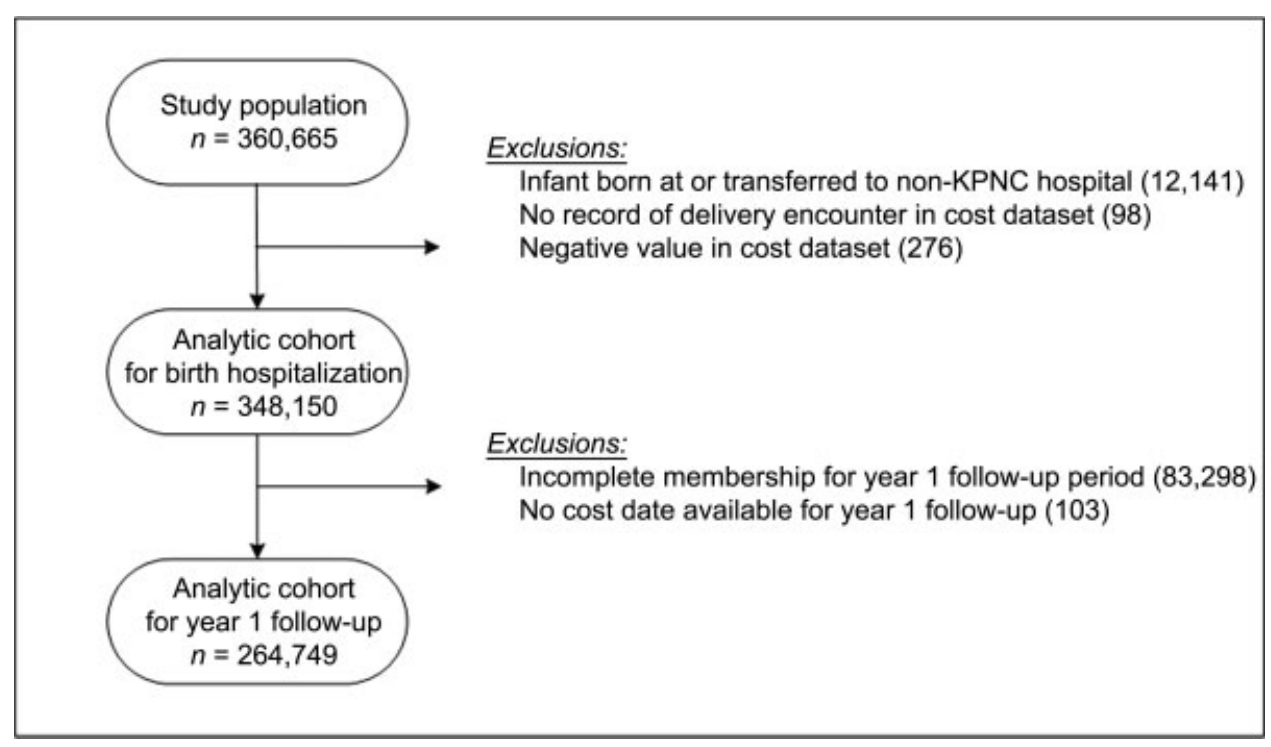

Fig. 1 Inclusion process for birth hospitalization and year 1 follow-up cohorts. 
provided by Kaiser Permanente, including pharmacy, laboratory, imaging, and home health services. CMIS integrates utilization data with the Kaiser Permanente general ledger. All costs in the ledger (apart from costs for insurance-related functions, such as marketing and membership accounting) are fully allocated to health care services. CMIS uses standard cost-accounting methods to allocate all building and administrative overhead. Estimates of inpatient costs are determined from nursing acuity scoring (GRASP), clinical service, and day of hospitalization. Surgical costs are estimated from the surgical service and time in the operating room. Inpatient pharmacy data are only available from 2010. Specific inpatient charges are not available. For services that were provided by non-Kaiser Permanente providers, but paid for by Kaiser Permanente, we used the charges of the non-Kaiser Permanente providers as the costs to Kaiser Permanente of these "outside" services. The impact of using charge data for non-Kaiser Permanente services was small; of all inpatient costs in the study data, only $0.86 \%$ of the dollars were from external charge data, and for outpatient costs the corresponding percentage was $0.89 \%$. Costs were normalized to $\$ 2,013$.

\section{Preterm Labor}

We identified maternal admissions for PTL by selecting inpatient encounters that had an International Disease Classification (ICD-9) code for PTL (644.0, 644.00, 644.03, 644.20, 644.21, V23.41) assigned. PTL admissions were classified as uncomplicated PTL if there were no other complicating diagnoses, such as preterm premature rupture of membranes (658., 658.10, 658.11, 658.13), chorioamnionitis (658.4x), preeclampsia/eclampsia $(642.5 x, 642.6 x, 642.7 x)$, cervical incompetence $(622.5,654.5 \mathrm{x}, 654.6 \mathrm{x})$, or bleeding/placenta previa/abruption (641.1x, 641.2x, 641.3x, 641.8x, 641.9x).

\section{Statistical Analysis}

We used linear regression to evaluate the incremental cost of care for each week of gestation compared with infants born at 40 weeks of gestation. We developed adjusted models, retaining variables that were significant at $p<0.05$ in bivariate analyses. We evaluated infant race/ethnicity, birth year, birth facility, mode of delivery, and SGA status. We developed models for cost of the birth hospitalization and cost of additional health care in the 1 st year of life, including additional inpatient care and outpatient costs. Our models yielded estimates for cost differences with 95\% confidence intervals for each GA group. The resulting values represent the percentage change from the reference group cost to the comparison group cost, as follows:

(cost of comparison group-cost of reference group)/cost of reference group

Outpatient costs included emergency department visits, outpatient clinic visits, outpatient therapies, and medication costs. To explore the contribution of the major neonatal morbidities to cost, we developed separate cost models that included these morbidities and adjusted for GA.

\section{Results}

We analyzed the costs of the birth hospitalization for 348,150 live born infants, of whom 264,749 (76.0\%) contributed cost and utilization data for both inpatient and outpatient care, for the initial year of life. The characteristics of the study cohort are displayed in -Table 1.

- Table 2 compares the cost and utilization associated with each individual week of GA, compared with the reference group of term infants with GA 38 to 40 weeks. Each week of prematurity from 37 to 25 weeks is associated with a statistically significant increase in birth hospitalization costs. Within this range, cost differences are seen to increase progressively with each decreasing week. The most extreme cost difference is observed in the 25 weeks category (a 5,609\% cost increase compared with the reference group), whereas those born closer to term have lesser but still significant cost differences, for example, infants born at 34, 35, and 36 weeks have costs increases of 470,178 , and $76 \%$, respectively. Postterm infants (41 or more weeks GA) also have significantly higher birth hospitalization costs than the reference group, albeit of lesser magnitude (a $4 \%$ increase). In utilization comparisons, similar relationships are seen among infants 37 to 25 weeks, the average lengths of stay (LOS) for each category increasing steadily with each decreasing week of GA. In this analysis, infants born at 25 weeks have the most extreme difference (median LOS 91 days, compared with the reference group's median LOS 2 days). Moderately preterm infants born at 34, 35, and 36 weeks have median LOS 8, 4, and 3 days, respectively. For infants born at 23 or 24 weeks, the comparative costs and utilization for preterm infants are also substantially, and significantly, higher than those of the reference group, but the inverse relationship seen from 37 down to 25 weeks is not sustained in these two GA groups, as higher mortality within the birth hospitalization results in fewer inpatient days for these infants, compared with premature infants born at higher GAs.

In examining drivers of cost, we assessed the rates by gestational week for the major morbidities of prematurity, as well as for mortality, and for a composite indicator of survival to discharge home with none of the major morbidities, among the subset of the cohort born at 23 to 32 weeks (-Table 3). These data demonstrate an appreciable reduction in mortality and morbidity with each 1-week increase in GA. Accordingly, the rate of intact survival increases steadily with each week GA. Mortality rates are highest among 23and 24-week infants (90.5 and 54.3\%, respectively); this explains their lower adjusted cost difference and shorter average LOS, compared with 25-week GA infants (- Table 2 ).

We examined additional health care costs and utilization in the 1st year of life. For cost comparisons we evaluated the cost differences of any additional hospitalizations occurring after initial discharge home, and for utilization comparisons we evaluated readmission rates, number of hospital days for readmissions, and the numbers of outpatient visits and emergency department visits (-Table 4). Unlike birth hospitalizations, cost differences for readmission hospitalizations did not follow a steady pattern by GA, although infants 
Table 1 Characteristics of study cohort $(n=348,150)$

\begin{tabular}{|c|c|c|c|c|c|c|}
\hline & \multicolumn{6}{|c|}{ Gestational age category ( $n$ ) } \\
\hline & \multicolumn{2}{|c|}{$\leq 33 \mathrm{wk}$} & \multicolumn{2}{|c|}{$34-36 \mathrm{wk}$} & \multicolumn{2}{|l|}{$\geq 37 \mathrm{wk}$} \\
\hline & \multicolumn{2}{|l|}{4,568} & \multicolumn{2}{|c|}{17,359} & \multicolumn{2}{|l|}{326,223} \\
\hline & $n$ & $\%$ & $n$ & $\%$ & $n$ & $\%$ \\
\hline Male & 2,459 & 53.8 & 9,567 & 55.1 & 166,162 & 50.9 \\
\hline \multicolumn{7}{|l|}{ Race/ethnicity } \\
\hline White & 1,503 & 32.9 & 6,472 & 37.3 & 131,371 & 40.3 \\
\hline Black & 625 & 13.7 & 1,475 & 8.5 & 22,436 & 6.9 \\
\hline Asian & 979 & 21.4 & 3,850 & 22.2 & 65,469 & 20.1 \\
\hline Hispanic & 1,180 & 25.8 & 4,311 & 24.8 & 82,104 & 25.2 \\
\hline Other/unknown & 281 & 6.2 & 1,251 & 7.2 & 24,843 & 7.6 \\
\hline Cesarean delivery & 2,362 & 51.7 & 5,315 & 30.6 & 74,759 & 22.9 \\
\hline Small for gestation age (SGA) & 180 & 3.9 & 512 & 3.0 & 5,023 & 1.5 \\
\hline Large for gestational age (LGA) & 137 & 3.0 & 1,102 & 6.4 & 14,151 & 4.3 \\
\hline Early onset sepsis & 65 & 1.4 & 25 & 0.1 & 133 & 0.0 \\
\hline Intracranial hemorrhage, severe & 110 & 2.4 & 2 & 0.0 & 13 & 0.0 \\
\hline Necrotizing enterocolitis & 98 & 2.2 & 2 & 0.0 & 6 & 0.0 \\
\hline Chronic lung disease & 389 & 8.5 & 17 & 0.1 & 45 & 0.0 \\
\hline Retinopathy of prematurity, severe & 42 & 0.9 & 0 & 0.0 & 0 & 0.0 \\
\hline Late sepsis/meningitis & 278 & 6.1 & 8 & 0.1 & 20 & 0.0 \\
\hline Assisted ventilation for $\geq 1 \mathrm{wk}$ & 819 & 17.9 & 68 & 0.4 & 110 & 0.0 \\
\hline Death after discharge & 293 & 6.4 & 33 & 0.2 & 272 & 0.1 \\
\hline Eligible for year 1 follow-up analyses ${ }^{\text {a }}$ & 3,326 & 72.8 & 13,071 & 75.3 & 248,467 & 76.2 \\
\hline
\end{tabular}

anfants with health plan membership in any of months 7-12 of life and cost data from the initial year of life, are included.

24 to 28 weeks had the highest cost differences. In utilization comparisons, however, there are clear patterns of increasing readmission rates, more outpatient visits and more emergency department visits for each gestational week, as GA decreases. Interestingly, year 1 hospitalization cost estimates for infants born at 34 to 37 weeks were significantly lower than the same for term infants (-Table 4). For 37-week infants, this may be at least partly explained by a slightly lower LOS. A better understanding of the causes of lower year 1 hospitalization costs for 34- to 36-week infants would require analysis of data representing diagnoses, procedures, medications, laboratory tests (types, frequencies, and results), and other potential markers of inpatient acuity and intensiveness of care which are beyond the scope of the data available for this study.

\section{Discussion}

Our analysis provides a summary of the costs associated with birth hospitalization and subsequent additional health care costs during the 1st year of life by week of gestation from a large, contemporary population-based dataset. It is not surprising that we found, as other studies have, an incremental increase in costs and utilization, by week of prematurity.
Our data also show that while health care utilization in the 1st year of life is increased in the preterm population, the birth hospitalization constitutes the substantial proportion of utilization for the more preterm infants. In our cohort, the sum of all encounter days after initial discharge home was less than the birth hospitalization length of stay, for all gestations $<34$ weeks. This is consistent with the findings of Mangham et al who found in England and Wales that birth hospitalization costs are responsible for $92.0 \%$ of the incremental costs per preterm survivor. ${ }^{22}$ Our data also highlight that while a large impact would result from delaying delivery by 1- or 2-week in the lowest GA groups, delaying delivery in moderately preterm infants by a week could have more financial impact because of the larger percentage of infants born at these GAs.

Interventions to prevent or delay preterm delivery should be evaluated across the GA spectrum. The impact on mortality and morbidity is undoubtedly higher in the lower GA groups; however, the financial burden on the health system may also be lessened substantially by delaying delivery in moderately and late preterm infants. Extremely low GA (ELGA) infants, defined as those born at $<28$ weeks, are $0.2 \%$ of our cohort, whereas moderately preterm infants (born at 31-36 weeks) are $5.8 \%$. Examining cost differences for moderately preterm infants by each individual week, compared with the estimate for the category that is just 1 week more mature, the percentage 
Table 2 Comparisons of cost and utilization for the birth hospitalization by week of gestational age, infants born at $\geq 23$ weeks gestational age ${ }^{\mathrm{a}}(n=348,150)$

\begin{tabular}{|l|l|l|l|l|l|l|}
\hline & \multicolumn{3}{|l}{ Cost difference } & \multicolumn{3}{l|}{ Length of stay, d } \\
\hline GA, wk & $\boldsymbol{n}$ & Percent increase $^{\text {b }}(\%)$ & $\mathbf{9 5 \%}$ Cl (\%) & $p$-Value & Median & IQR \\
\hline 23 & 105 & 1,145 & $1,043-1,26 \%$ & $<0.01$ & 0 & $0-1$ \\
\hline 24 & 129 & 3,969 & $3,665-4,307$ & $<0.01$ & 28 & $0-105$ \\
\hline 25 & 146 & 5,609 & $5,206-6,054$ & $<0.01$ & 91 & $73-107$ \\
\hline 26 & 183 & 5,348 & $5,003-5,725$ & $<0.01$ & 76 & $64-88$ \\
\hline 27 & 217 & 4,905 & $4,613-5,222$ & $<0.01$ & 66 & $56-78$ \\
\hline 28 & 279 & 3,971 & $3,760-4,197$ & $<0.01$ & 56 & $48-68$ \\
\hline 29 & 317 & 3,163 & $3,004-3,333$ & $<0.01$ & 46 & $40-55$ \\
\hline 30 & 416 & 2,629 & $2,513-2,753$ & $<0.01$ & 38 & $32-47$ \\
\hline 31 & 568 & 1,915 & $1,841-1,993$ & $<0.01$ & 29 & $25-37$ \\
\hline 32 & 904 & 1,339 & $1,297-1,382$ & $<0.01$ & 21 & $17-28$ \\
\hline 33 & 1,304 & 833 & $810-857$ & $<0.01$ & 14 & $11-19$ \\
\hline 34 & 2,707 & 470 & $460-480$ & $<0.01$ & 8 & $6-13$ \\
\hline 35 & 4,810 & 178 & $175-182$ & $<0.01$ & 4 & $3-6$ \\
\hline 36 & 9,842 & 76 & $75-78$ & $<0.01$ & 3 & $2-4$ \\
\hline 37 & 22,990 & 18 & $17-19$ & $<0.01$ & 2 & $1-3$ \\
\hline $38-40$ & 257,309 & Ref & Ref & Ref & 2 & $1-2$ \\
\hline $41+$ & 45,924 & $4 \%$ & $4-55$ & $<0.01$ & 2 & $1-2$ \\
\hline
\end{tabular}

Abbreviations: $\mathrm{Cl}$, confidence interval; GA, gestational age; IQR, interquartile range.

ancluding survivors to discharge home and infants who died during the birth hospitalization.

${ }^{\mathrm{b}}$ As compared with 38 to 40 weeks gestational age category.

change in costs for the birth hospitalization are sharply reduced with each increasing week in GA among these infants. For example, infants born at 33 weeks have a percentage change of $833.2 \%$, whereas for those born at 34 weeks the estimate is 469.7\%. Moving from 34 to 35 weeks decreases the percentage change from 469.7 to $178.4 \%$, from 35 to 36 weeks, 178.4 to $76.2 \%$, and from 36 to 37 weeks, 76.2 to $17.8 \%$, respectively (-Table 2). These dramatic shifts are consistent with, and explained by, the corresponding decreased rates of NICU admission and shorter LOS seen for each of these GA comparisons (-Table 2).

Our approach was estimating cost that has several advantages compared with other studies. First, we are employing a modern, population-based cohort. Our data come from infants born between 2000 and 2011. Much of the literature on costs associated with prematurity in the United States comes from birth cohorts that included the late 1980s and the early $1990 s,{ }^{14-20,24}$ before the widespread introduction of surfactant in the early 1990s and its dramatic impact on mortality and morbidity. ${ }^{32}$ Our data also represent the period after the National Institutes of Health consensus and recommendation, issued in 1994, that antenatal corticosteroids (ANS) be administered to all women at risk for preterm birth between 24 and 34 weeks of gestation. ${ }^{33}$ While we report on a single health system, our cohort is quasi population-based. KPNC insures over $1 / 3$ of the population of Northern California. The KPNC membership is diverse in race and ethnicity, reflecting its
Northern California population base ( - Table 1 ). The birth cohort of $>35,000$ births each year is larger than the birth cohorts of 15 states in the United States. ${ }^{34}$ While we report on a single health system, the system is composed of a mix of facilities with level II and level III nurseries, in which some facilities function as regional referral centers for cases with the highest acuity or in need of specialized care. Second, we calculate costs directly. Most studies have relied on cost-charge ratios to calculate costs. ${ }^{10,11,18,20}$ Charges are not accurate measures of cost secondary to differential markups for various components of health care that may also differ among institutions or payer. ${ }^{24,35}$ Cost-charge ratios cannot fully correct for these differences. The cost data which underlie our estimated cost differences are based on actual expenditures from the KPNC general ledger, eliminating the possibility of such facilitylevel differences in markup or discount rates. The KPNC cost data source and methods used in our analyses are previously described in several publications. ${ }^{36-38}$ Lastly, we had access to data from a variety of sources, including neonatal research databases, ${ }^{29}$ instead of purely administrative data, such as hospital discharge records and birth certificate data. Because of our data sources, we could adjust for other potentially significant factors in cost and had better identification of neonatal morbidities, compared with relying on ICD-9 codes. In addition, we extracted GA from the obstetrical medical record. Previous studies have reported errors in GA when using birth certificate data. ${ }^{10,20,39}$ 
Incremental Cost of Prematurity by Week of Gestational Age Walsh et al. e81

Table 3 Incidence of major morbidity and mortality during the birth hospitalization, by gestational week, infants 23 to 32 weeks $(n=3,264)$

\begin{tabular}{|l|l|l|l|l|l|l|l|l|l|l|}
\hline $\begin{array}{l}\text { GA } \\
(\mathbf{w k})\end{array}$ & $\mathbf{n}$ & $\begin{array}{l}\text { Intracranial } \\
\text { hemorrhage, } \\
\text { severe (\%) }\end{array}$ & $\begin{array}{l}\text { Necrotizing } \\
\text { enterocolitis } \\
(\%)\end{array}$ & $\begin{array}{l}\text { Chronic } \\
\text { lung } \\
\text { disease } \\
(\%)\end{array}$ & $\begin{array}{l}\text { Retinopathy } \\
\text { of prematurity, } \\
\text { severe (\%) }\end{array}$ & $\begin{array}{l}\text { Early } \\
\text { sepsis or } \\
\text { meningitis } \\
(\%)\end{array}$ & $\begin{array}{l}\text { Late } \\
\text { sepsis or } \\
\text { meningitis } \\
(\%)\end{array}$ & $\begin{array}{l}\text { Assisted } \\
\text { ventilation } \\
\geq \mathbf{1} \text { wk (\%) }\end{array}$ & $\begin{array}{l}\text { Mortality } \\
\text { in the birth } \\
\text { hospitalization } \\
(\%)\end{array}$ & $\begin{array}{l}\text { Survival } \\
\text { with no } \\
\text { major } \\
\text { morbidity } \\
(\%)\end{array}$ \\
\hline 23 & 105 & 6.7 & 2.9 & 7.6 & 1.0 & 0.0 & 6.7 & 15.2 & 90.5 & 0.0 \\
\hline 24 & 129 & 15.5 & 9.3 & 32.6 & 9.3 & 6.2 & 31.0 & 59.7 & 54.3 & 0.0 \\
\hline 25 & 146 & 15.1 & 5.5 & 46.6 & 10.3 & 5.5 & 34.9 & 76.7 & 21.9 & 4.8 \\
\hline 26 & 183 & 5.5 & 4.9 & 37.2 & 6.6 & 5.5 & 19.7 & 72.7 & 13.7 & 14.8 \\
\hline 27 & 217 & 6.5 & 3.7 & 28.1 & 0.9 & 3.7 & 16.1 & 59.5 & 6.0 & 27.7 \\
\hline 28 & 279 & 2.5 & 5.0 & 19.7 & 0.0 & 2.9 & 12.9 & 45.9 & 6.8 & 43.0 \\
\hline 29 & 317 & 3.8 & 4.4 & 8.2 & 0.0 & 1.9 & 8.8 & 27.4 & 3.2 & 60.6 \\
\hline 30 & 416 & 1.9 & 1.4 & 5.1 & 0.0 & 1.7 & 3.6 & 13.2 & 0.7 & 78.9 \\
\hline 31 & 568 & 0.7 & 1.1 & 3.0 & 0.0 & 0.7 & 2.8 & 7.8 & 0.4 & 87.9 \\
\hline 32 & 904 & 0.6 & 1.0 & 1.2 & 0.0 & 0.2 & 1.3 & 2.2 & 0.6 & 94.4 \\
\hline
\end{tabular}

Abbreviation: GA, gestational age.

Table 4 Incremental cost difference by week of gestational age for hospitalization and other health service costs incurred after initial discharge home, during the first year of life $(n=264,749)$

\begin{tabular}{|c|c|c|c|c|c|c|c|c|c|c|c|c|c|}
\hline \multirow{3}{*}{$\begin{array}{l}\text { GA } \\
\text { (wk) }\end{array}$} & \multirow{2}{*}{\multicolumn{4}{|c|}{$\begin{array}{l}\text { Year } 1 \text { hospitalization }^{\mathrm{a}} \text { costs } \\
\text { Adjusted }^{\mathrm{c}} \text { cost difference (\%) }\end{array}$}} & \multicolumn{9}{|c|}{ Year 1 health care utilization } \\
\hline & & & & & \multirow{2}{*}{$\begin{array}{l}\begin{array}{l}\text { All } \\
\text { infants }\end{array} \\
n\end{array}$} & \multicolumn{2}{|c|}{$\begin{array}{l}\text { Ever } \\
\text { readmitted }\end{array}$} & \multicolumn{2}{|c|}{$\begin{array}{l}\text { Hospital days, } \\
\text { if readmitted } \\
(n)\end{array}$} & \multicolumn{2}{|c|}{$\begin{array}{l}\text { Outpatient } \\
\text { visits }(n)\end{array}$} & \multicolumn{2}{|c|}{$\begin{array}{l}\text { Emergency } \\
\text { department } \\
\text { visits }(n)\end{array}$} \\
\hline & $\begin{array}{l}\text { Eligible } \\
\text { for year } 1 \\
\text { analyses }{ }^{d} \\
(n)\end{array}$ & $\begin{array}{l}\text { Estimate } \\
\text { (\%) }\end{array}$ & $95 \% \mathrm{Cl}(\%)$ & $p$-Value & & $n$ & $\%$ & Median & IQR & Median & IQR & Median & IQR \\
\hline 23 & 2 & -92.6 & -97.8 to -42.2 & $<0.01$ & 4 & 1 & 25.0 & 34 & $34-34$ & 26 & $17.5-35.5$ & 1 & $1-4$ \\
\hline 24 & 19 & 73.6 & 9.4-199.3 & 0.03 & 43 & 8 & 18.6 & 1.5 & $1-8$ & 19 & $15-24$ & 1 & $1-2$ \\
\hline 25 & 48 & 191.3 & $115.8-306.3$ & $<0.01$ & 92 & 32 & 34.8 & 3.5 & $2-9$ & 22 & $15-23$ & 1 & $1-2$ \\
\hline 26 & 48 & 164.2 & $95.5-268.7$ & $<0.01$ & 128 & 28 & 21.9 & 2.5 & $1-7$ & 18 & $13-23$ & 2 & $1-2$ \\
\hline 27 & 55 & 101.1 & $51.6-174.3$ & $<0.01$ & 154 & 29 & 18.8 & 3 & $1-10$ & 17 & $13-22$ & 1 & $1-2$ \\
\hline 28 & 54 & 73.2 & $30.4-136.6$ & $<0.01$ & 199 & 33 & 16.6 & 3 & $1-13$ & 17 & $13-22$ & 1 & $1-2$ \\
\hline 29 & 80 & -23.9 & -39.9 to -1.7 & 0.03 & 238 & 40 & 16.8 & 2 & $1-6.5$ & 16 & $13-21$ & 1 & $1-2$ \\
\hline 30 & 92 & -0.2 & -20.0 to -26.5 & 0.99 & 326 & 55 & 16.9 & 2 & $1-4$ & 15 & $12-20$ & 1 & $1-2$ \\
\hline 31 & 92 & -2.1 & -21.4 to 24.1 & 0.85 & 449 & 47 & 10.5 & 3 & $1-6$ & 15 & $12-19$ & 1 & $1-2$ \\
\hline 32 & 137 & 26.5 & $5.4-53.6$ & 0.01 & 694 & 73 & 10.5 & 2 & $1-5$ & 12 & $9-17$ & 1 & $1-2$ \\
\hline 33 & 150 & 1.3 & -14.8 to 21.8 & 0.88 & 984 & 90 & 9.2 & 2 & $1-4$ & 11 & $8-15$ & 1 & $1-2$ \\
\hline 34 & 275 & 20.1 & $5.4-37.5$ & 0.01 & 2,056 & 180 & 8.8 & 2 & $2-5$ & 11 & $8-14$ & 1 & $1-2$ \\
\hline 35 & 610 & -11.8 & -19.3 to -3.4 & 0.01 & 3,612 & 479 & 13.3 & 2 & $1-3$ & 11 & $8-15$ & 1 & $1-2$ \\
\hline 36 & 1,211 & -16.3 & -21.5 to -10.6 & $<0.01$ & 7,393 & 1,001 & 13.5 & 2 & $1-3$ & 11 & $8-14$ & 1 & $1-2$ \\
\hline 37 & 2,618 & -20.4 & -23.9 to -16.6 & $<0.01$ & 17,442 & 2,113 & 12.1 & 2 & $1-2$ & 10 & $8-13$ & 1 & $1-2$ \\
\hline $38-40$ & 16,153 & Ref & Ref & Ref & 196,376 & 12,591 & 6.4 & 2 & $1-3$ & 10 & $8-13$ & 1 & $1-1$ \\
\hline $41+$ & 2,336 & 25.0 & $19.1-31.3$ & $<0.01$ & 34,559 & 1,720 & 5.0 & 2 & $1-3$ & 10 & $8-13$ & 1 & $1-1$ \\
\hline
\end{tabular}

Abbreviations: $\mathrm{Cl}$, confidence interval; GA, gestational age; IQR, interquartile range.

${ }^{a}$ Hospitalization costs incurred during inpatient admissions and admissions to skilled nursing facilities, excluding the birth hospitalization.

beadmissions include only inpatient acute care encounters.

${ }^{\mathrm{c}}$ Adjusted by race and small gestational age.

${ }^{\mathrm{d}}$ Infants with health plan membership in any of months 7 to 12 of life and cost data for the initial year of life, are included. 
Our study also has some limitations that should be recognized. The study is of a single health system, so costs within the KPNC system may be lower or higher than other individual hospitals and may not be generalizable. Although it was a single health system, we did observe variation in costs between the facilities within the system. Additionally, our cost methodology used did not include individual costs.

\section{Conclusions}

In this study, we sought to estimate the incremental impact of each week of prematurity on costs and over the 1st year of life. Using a recent, large, and diverse cohort, linked to high quality cost and outcomes data, we have provided estimates based on the actual costs to an integrated health care system which are attributable to decreasing GA. Our estimates of the cost differences by week of GA estimates could support analyses exploring the potential cost savings attributable to interventions that delay or prevent premature labor. Cost differences were most extreme at the lower range of gestation; however, infants born moderately preterm (31-36 weeks) also contribute substantially to the burden, as they represent a higher proportion of total births.

\section{Disclosure}

The analyses reported in this study were funded by GlaxoSmithKline (GSK) under study GHO-11-3804. Author L.B. was a GSK employee at the time of the study. The authors were not compensated by GSK for the preparation of this publication. The remaining authors have nothing to disclose.

\section{Conflict of Interest}

Dr. L.B. reports other from GlaxoSmithKline, during the conduct of the study; personal fees from GlaxoSmithKline, outside the submitted work.

E.M.W. reports other from GlaxoSmithKline, during the conduct of the study.

\section{References}

1 Alfirevic Z, Stampalija T, Roberts D, Jorgensen AL. Cervical stitch (cerclage) for preventing preterm birth in singleton pregnancy. Cochrane Database Syst Rev 2012;(04):CD008991

2 Nijman TA, van Vliet EO, Koullali B, Mol BW, Oudijk MA. Antepartum and intrapartum interventions to prevent preterm birth and its sequelae. Semin Fetal Neonatal Med 2016;21(02):121-128

3 Mackenzie R, Walker M, Armson A, Hannah ME. Progesterone for the prevention of preterm birth among women at increased risk: a systematic review and meta-analysis of randomized controlled trials. Am J Obstet Gynecol 2006;194(05):1234-1242

4 Platt MJ. Outcomes in preterm infants. Public Health 2014;128 (05):399-403

5 Manuck TA, Rice MM, Bailit JL, et al; Eunice Kennedy Shriver National Institute of Child Health and Human Development Maternal-Fetal Medicine Units Network. Preterm neonatal morbidity and mortality by gestational age: a contemporary cohort. Am J Obstet Gynecol 2016;215(01):103.e1-103.e14

6 Boyle EM, Poulsen G, Field DJ, et al. Effects of gestational age at birth on health outcomes at 3 and 5 years of age: population based cohort study. BMJ 2012;344:e896
7 Natarajan G, Shankaran S. Short- and long-term outcomes of moderate and late preterm infants. Am J Perinatol 2016;33(03):305-317

8 Ancel PY, Goffinet F, Kuhn P, et al; EPIPAGE-2 Writing Group. Survival and morbidity of preterm children born at 22 through 34 weeks' gestation in France in 2011: results of the EPIPAGE-2 cohort study. JAMA Pediatr 2015;169(03):230-238

9 Saigal S, Doyle LW. An overview of mortality and sequelae of preterm birth from infancy to adulthood. Lancet 2008;371 (9608):261-269

10 Phibbs CS, Schmitt SK. Estimates of the cost and length of stay changes that can be attributed to one-week increases in gestational age for premature infants. Early Hum Dev 2006;82(02):85-95

11 Russell RB, Green NS, Steiner CA, et al. Cost of hospitalization for preterm and low birth weight infants in the United States. Pediatrics 2007;120(01):e1-e9

12 Black L, Hulsey T, Lee K, Parks DC, Ebeling MD. Incremental hospital costs associated with comorbidities of prematurity. Manag Care 2015;24(12):54-60

13 Barradas DT, Wasserman MP, Daniel-Robinson L, et al. Hospital utilization and costs among preterm infants by payer: nationwide inpatient sample, 2009. Matern Child Health J 2016;20(04):808-818

14 Feldman WE, Wood B. The economic impact of high-risk pregnancies. J Health Care Finance 1997;24(01):64-71

15 Kilpatrick SJ, Schlueter MA, Piecuch R, Leonard CH, Rogido M, Sola A. Outcome of infants born at 24-26 weeks' gestation: I. Survival and cost. Obstet Gynecol 1997;90(05):803-808

16 Luke B, Bigger HR, Leurgans S, Sietsema D. The cost of prematurity: a case-control study of twins vs singletons. Am J Public Health 1996;86(06):809-814

17 Petrou S, Mehta Z, Hockley C, Cook-Mozaffari P, Henderson J, Goldacre M. The impact of preterm birth on hospital inpatient admissions and costs during the first 5 years of life. Pediatrics 2003;112(6 Pt 1):1290-1297

18 St John EB, Nelson KG, Cliver SP, Bishnoi RR, Goldenberg RL. Cost of neonatal care according to gestational age at birth and survival status. Am J Obstet Gynecol 2000;182(1 Pt 1):170-175

19 Chollet DJ, Newman JF Jr., Sumner AT. The cost of poor birth outcomes in employer-sponsored health plans. Med Care 1996;34 (12):1219-1234

20 Gilbert WM, Nesbitt TS, Danielsen B. The cost of prematurity: quantification by gestational age and birth weight. Obstet Gynecol 2003;102(03):488-492

21 Korvenranta E, Linna M, Rautava L, et al; Performance, Effectiveness, and Cost of Treatment Episodes (PERFECT) Preterm Infant Study Group. Hospital costs and quality of life during 4 years after very preterm birth. Arch Pediatr Adolesc Med 2010;164(07):657-663

22 Mangham LJ, Petrou S, Doyle LW, Draper ES, Marlow N. The cost of preterm birth throughout childhood in England and Wales. Pediatrics 2009;123(02):e312-e327

23 Ringborg A, Berg J, Norman M, Westgren M, Jönsson B. Preterm birth in Sweden: what are the average lengths of hospital stay and the associated inpatient costs? Acta Paediatr 2006;95(12): 1550-1555

24 Rogowski J. Measuring the cost of neonatal and perinatal care. Pediatrics 1999;103(1, Suppl E):329-335

25 Hall ES, Greenberg JM. Estimating community-level costs of preterm birth. Public Health 2016;141:222-228

26 van Baaren GJ, Peelen MJ, Schuit E, et al. Preterm birth in singleton and multiple pregnancies: evaluation of costs and perinatal outcomes. Eur J Obstet Gynecol Reprod Biol 2015; 186:34-41

27 Schmitt SK, Sneed L, Phibbs CS. Costs of newborn care in California: a population-based study. Pediatrics 2006;117(01):154-160

28 Fenton TR. A new growth chart for preterm babies: Babson and Benda's chart updated with recent data and a new format. BMC Pediatr 2003;3:13

29 Escobar GJ, Fischer A, Kremers R, Usatin MS, Macedo AM, Gardner MN. Rapid retrieval of neonatal outcomes data: the Kaiser 
Permanente Neonatal Minimum Data Set. Qual Manag Health Care 1997;5(04):19-33

30 Bell MJ. Neonatal necrotizing enterocolitis. N Engl J Med 1978;298 (05):281-282

31 Network VO. Manual of operations. 2016 Available from: https:// vtoxford.zendesk.com/hc/en-us/categories/360000861394-Manuals-and-Forms. Accessed March 11, 2019

32 Schwartz RM, Luby AM, Scanlon JW, Kellogg RJ. Effect of surfactant on morbidity, mortality, and resource use in newborn infants weighing 500 to 1500 g. N Engl J Med 1994;330(21): 1476-1480

33 NIH Consensus Development Panel on the Effect of Corticosteroids for Fetal Maturation on Perinatal Outcomes. Effect of corticosteroids for fetal maturation on perinatal outcomes. JAMA 1995;273(05):413-418

34 Hamilton BE, Martin JA, Osterman MJ, Curtin SC, Matthews TJ. Births: final data for 2014. Natl Vital Stat Rep 2015;64(12):1-64
35 Finkler SA. The distinction between cost and charges. Ann Intern Med 1982;96(01):102-109

36 Ray GT, Croen LA, Habel LA. Mothers of children diagnosed with attention-deficit/hyperactivity disorder: health conditions and medical care utilization in periods before and after birth of the child. Med Care 2009;47(01):105-114

37 Ray GT, Levine P, Croen LA, Bokhari FA, Hu TW, Habel LA. Attention-deficit/hyperactivity disorder in children: excess costs before and after initial diagnosis and treatment cost differences by ethnicity. Arch Pediatr Adolesc Med 2006;160 (10):1063-1069

38 Ray GT, Mertens JR, Weisner C. The excess medical cost and health problems of family members of persons diagnosed with alcohol or drug problems. Med Care 2007;45(02):116-122

39 Alexander GR, Himes JH, Kaufman RB, Mor J, Kogan M. A United States national reference for fetal growth. Obstet Gynecol 1996;87 (02):163-168 